\title{
Protection of Marine Biodiversity from Pollution: Legal Strategies in Malaysia
}

\author{
Maizatun Mustafa and Mariani Ariffin
}

\begin{abstract}
This paper discusses sources of marine pollution in Malaysia and examines existing provisions under the law relevant to the control of such pollution. Being a maritime nation as well as one of the top biodiversity-rich countries in the world, it is important for Malaysia to give its full commitment in conserving her mega-diverse ecosystems, including that of the richly endowed seas. At present, the well being of Malaysia's marine biodiversity is facing increasing threat from various sources, notably that of land-based and vessel-based pollution. Malaysia takes pollution issue seriously, and joins other key maritime nations in enhancing her legal regime in dealing with marine pollution. This paper seeks to highlight Malaysia's continuous effort towards marine pollution control through the application of both domestic and international law. Significantly, such effort can be used as a reference by other maritime nations for the purpose of collective marine environmental protection and biodiversity conservation.
\end{abstract}

Index Terms-Environmental law, Marine biodiversity, Marine pollution, Marine pollution law, Pollution control.

\section{INTRODUCTION}

Malaysia is geographically divided into two parts, Peninsula Malaysia or West Malaysia, and East Malaysia, with a total coastline of $4800 \mathrm{~km}$. Peninsula Malaysia is bounded by seas on all sides except in the north where it is connected to the Asian mainland via Thailand. Both West and East Malaysia are separated by the South China Sea, while the west coast of West Malaysia is bordered by the Straits of Malacca with Andaman Sea to the north and Java Sea to the south.

From the perspective of biodiversity, Malaysia has one of the largest continental shelf areas and is considered to contain the greatest species diversity of marine life in the world. These rich marine resources are important to Malaysia's socio-economic development. Apart from that, the marine environment contains living systems that support a multitude of life and perform important ecological functions [1]. Therefore it is pertinent that the marine biological diversity be conserved and protected. Thus, the quality of the marine water of Malaysia plays an important role in the conservation of marine resources. Inevitably, any sources of pollution would cause a big threat to these resources.

Over the years, Malaysia's marine environment continues to face serious pressure particularly due to pollution.

Manuscript received November 18, 2011; revised November 30, 2011.

Maizatun Mustafa is with the Legal Practice Department, Ahmad Ibrahim Kulliyyah of Laws, International Islamic University Malaysia, Jalan Gombak 53100 Kuala Lumpur, Malaysia(e-mail: maizatun@iium.edu.my).

Mariani Ariffin is with the Department of Environmental Management, Faculty of Environmental Studies, Universiti Putra Malaysia, 43400 Serdang Selangor Malaysia (e-mail: mariani@env.upm.edu.my).
Pollution from land-based sources, mainly as consequences of urbanization and industrialization along the coastal areas of Malaysia, has been identified as the major contributors towards marine pollution [2]. Another source of marine pollution is that of vessel-based. By virtue of its geographical location, Malaysia is strategically located at the conjunction of the Straits of Malacca and the South China Sea, which serve as a major commercial shipping route between the Indian Ocean and the Pacific Ocean.

The Straits of Malacca is most susceptible to vessel-based marine pollution such as oil and grease especially in recent years due to the heavy volume of shipping that uses it [2]. In the year 2010 alone, more than 75000 vessels have passed through the Straits [3]. Thus, vessels discharges such as tank cleaning, deballasting, bilging and bunkering are the most significant activities contributing to the oil and grease in the marine water. With the expansion of world trade, the traffic volume was expected to increase rapidly which would significantly increase the risk of vessels accidents and marine pollution. By nature, oil is toxic to marine life. If oil spill reaches the shoreline, it interacts with sediments, vegetation, and habitats of wildlife and humans, causing erosion and contamination. Oil spill could remain for years in the sediment and marine environment, causing long-term effects to the marine biodiversity. It is important for Malaysia to address the threats posed by the land-based and vessel-based pollution to ensure the sustainability of marine biodiversity [4].

For Malaysia and other maritime countries, issues relating to the conservation of marine biodiversity are very wide and complex. They include, among others, preservation of biological productivity, clean surface of the ocean, and preservation of food resources. Since pollution has been identified to be one of the major threats to marine environment, the control of marine pollution is therefore a prerequisite in the conservation of marine ecosystem.

According to the 1982 United Nations Convention on the Law of the Sea, pollution of the marine means "the introduction by man, directly or indirectly, substances or energy into the marine environment (including estuaries) which results or is likely to result in such deleterious effects as harm to living resources and marine life, hazard to human health, hindrance to marine activities including fishing and other legitimate uses of the sea, impairment of quality for use of sea water and reduction of amenities". The discharge of pollutants into the marine environment must therefore be controlled effectively as they are hazardous to marine life, the marine ecosystem and human health. In this regard, law can be considered as an important means of controlling pollution, and have been relied on by Malaysia in dealing with marine pollution. 
In the case of Malaysia, the control of marine pollution would inevitably involve both domestic and international laws. It is possible for marine pollution to extent beyond boundaries of states requiring the intervention of international law. Malaysia, being a sovereign state has the liberty to deal with its own territories. For the purpose of implementing the law, by virtue of the Malaysian Emergency (Essential Powers) Ordinance 1969, Malaysia's jurisdiction is confined to the limit of her territorial waters of 12 nautical miles only. On this basis, Malaysia is given a total sovereignty within these waters, allowing her to enforce specific domestic laws which include that of pollution control.

In addition, Malaysia also proclaimed her 200 nautical miles of the exclusive economic zone (EEZ), in line with article 5 of the United Nations Conventions on the Law of the Sea 1982 (UNCLOS), and is incorporated into the domestic law, namely the Exclusive Economic Zone Act 1984. With the existence of the EEZ regime, Malaysia holds special privileges and responsibilities as provided in section 10 of the Act. They include, for environmental protection purposes, the control of the discharge of oil and pollutant into the EEZ. By virtue of Malaysia's jurisdictional rights over its territorial waters and the EEZ, a number of legislations have been enacted that forms the country's maritime legal structure, pertinent to marine pollution. These legislations are examined below.

\section{The ENVIRONMENTAL QUALITY ACT 1974}

\section{A. Inland Water Pollution}

As already mentioned, land-based sources of pollution are the significant contributors towards the pollution of Malaysia’s marine environment [5]. They include industrial wastes, agricultural wastes, domestic sewage and siltation. There are a variety of pathways for land-based pollutants to reach coastal and marine waters, either directly or indirectly. According to the Department of Environment Malaysia, the main cause of river pollution in Malaysia comes from domestic sewage treatment plants, industries, commercial areas and urban diffuse sources [2][6]. Apart from that, land development and urbanization activities in Malaysia also significantly contributed to pollution of rivers. With more than 150 river mouths located along the coastal areas of Malaysia, they become conduits for pollutants to enter coastal waters. These rivers that flow into the sea would therefore play a significant role in influencing the quality of marine environment.

The main legislation in Malaysia to control marine pollution from land-based sources is the Environmental Quality Act 1974. This Act can be considered as the most comprehensive legislation introduced to deal with environmental protection and pollution control including that of marine pollution.

One specific method applied by the Act to regulate pollution discharge is that of ambient environmental quality standards, or acceptable conditions. The term "acceptable conditions" presupposes an environmental standard, which will be used as a baseline criterion of the acceptability or restriction stipulated in the Act. Parameters limit for acceptable conditions of various pollution sources are provided in relevant Regulations gazetted under the Act. Pollution is allowed to be discharged as long as it is within the limit of acceptable conditions. Otherwise, it would be an offence, unless specific contravention licence is applied and approved.

Under the Act, the extent of the pollutants of inland water quality is measured by a water quality index of six parameters. They are Dissolved Oxygen; Biochemical Oxygen Demand; Chemical Oxygen Demand; Ammoniacal Nitrogen; Suspended Solids; and $\mathrm{pH}$. The water Quality Index also serves as a basis for environmental assessment of a watercourse in relation to pollution load categorization and designation of classes of beneficial uses.

In relation to land-based pollution, restriction on the discharge of pollution into the inland waters based on acceptable conditions limits is provided in section 25 of the Environmental Quality Act 1974. The term "inland water" is extensively defined by this Act to include "any reservoir, pond, lake, river, stream, canal, drain, spring or well, or any part of the sea above the low water line along the coast, or any other body of natural or artificial surface or subsurface water". Different types of inland water effluents are controlled by the Act under specific parameters limit of acceptable conditions as provided in the relevant Regulations of the Act. They include the Environmental Quality (Prescribed Premises)(Crude Palm Oil) Regulations 1977; and the Environmental Quality (Prescribed Premises)(Raw Natural Rubber) Regulations 1978 that contain parameters limit for the discharge from rubber and palm oil industries. Whereas Environmental Quality (Sewage) Regulations 2009 and the Environmental Quality (Industrial Effluent) Regulations 2009 contain parameters limit to regulate the discharge of pollutants from sewage and industrial wastes.

According to the Environmental Quality Act 1974, those who discharge effluents into the inland water exceeding the parameters limit prescribed in the said Regulations without any licence may be held liable for an offence. Section 25 imposes penalty in the form of fine of up to Ringgit Malaysia (RM) 100000 or imprisonment of up to five years to any person found guilty of the offence.

\section{B. Marine Pollution}

With regard to the marine and coastal waters, their quality is appraised by comparing certain selected parameters to determine the degree of pollution from land-based sources as well as from the sea that can pose threats to the marine resources. These parameters are Escherichia coli (E-coli); oil and grease; total suspended solids, arsenic, cadmium, total chromium, copper, lead and mercury. Whereas, parameters used for the in-situ measurements are temperature, $\mathrm{pH}$, dissolved oxygen, conductivity, salinity, turbidity and tarball [2].

Two specific provisions are provided by the Environmental Quality Act 1974 to control of the discharge of wastes and oil into the sea [7]. Specifically, section 27 prohibits any person from discharging or spilling any oil or mixture containing oil into Malaysian waters. Anyone who contravenes this prohibition shall be subjected to a fine of up 
to half a million ringgit, or imprisonment of up to five years or both. However, under certain circumstances, special defenses are granted to any person against the imposition of liability under section 27. These defences, as provided in section 28, include situations where discharge or spillage was done for the purpose of securing the safety of the vessel; for purposes of saving human lives; as a result of damage to the vessel; as a result of a leakage; or as a result of an effluent produced by operation for the refining of oil.

With regard to section 29, a prohibition is imposed on any person against discharging environmentally hazardous substances, pollutants or wastes into the Malaysian waters. The terms "environmentally hazardous substance", "pollutants", and "wastes" are given their respective definitions by the Act to ensure comprehensive coverage of discharges that may cause pollution to the marine environment.

Specifically, the Act defines the term "environmentally hazardous substances" as "any natural or artificial substances including any raw material, whether in a solid, semi-solid or liquid form, or in the form of gas or vapour, or in a mixture of at least two of these substances, or any living organism intended for any environmental protection, conservation and control activity, which can cause pollution”. On the other hand, "pollutants" is defined as "any natural or artificial substances, whether in a solid, semi-solid or liquid form, or in the form of gas or vapour, or in a mixture of at least two of these substances, or any objectionable odour or noise or heat emitted, discharged or deposited or is likely to be emitted, discharged or deposited from any source which can directly or indirectly cause pollution and includes any environmentally hazardous substances". Whereas the term "waste" is defined to include "any matter prescribed to be scheduled waste, or any matter whether in a solid, semisolid or liquid form, or in the form of gas or vapour which is emitted, discharged or deposited in the environment in such volume, composition or manner as to cause pollution”. Under the Act, penalty similar to that of section 27 will be imposed on anyone who contravenes section 29. However, unlike section 27, no defence is allowed for the contravention of section 29.

\section{Scheduled Wastes}

Another form of pollution control under the Environmental Quality Act 1974 which is significant to control marine pollution is section 34B concerning the prohibition against the depositing of scheduled wastes. The handling of scheduled wastes or toxic and hazardous wastes, including their method of disposing, is strictly regulated by the Act [8]. The lists of wastes that constitute "scheduled wastes" for the purpose of the Environmental Quality Act 1974 can be found in the Environmental Quality (Scheduled Wastes) Regulations 2005. They include wastes that can cause adverse impact on the marine environment. Specifically, under section $34 \mathrm{~B}$, it is a prohibition to discharge oil tanker sludges and oil water mixture such as ballast water into the Malaysian waters without written approval from the relevant authority [9]. Penalty imposed to any person who contravene this prohibition is a fine not exceeding Ringgit Malaysia (RM) 500000, or to jail for term of up to five years, or both

\section{Environmental Impact Assessment}

In Malaysia, while the marine area around the Straits of Malacca may be facing pollution from vessel-based sources, the area within the South China Sea is facing pollution as a result of off-shore oil and gas exploration activities. Considering the vital role petroleum industry plays in the Malaysian economy, it is thus subject to direct government control. However, from an ecological perspective, there is a persistent concern over the adverse impacts of oil and gas upstream activities on the marine environment, particularly that of pollution [10].

At present, the regulation of such activities is within the ambit of the Environmental Quality Act 1974 through section 34A on the requirement of environmental impact assessment (EIA). Whereas activities subject to EIA are prescribed under the Environmental Quality (Prescribed Activities) (Environmental Impact Assessment) Order 1987.

In relation upstream oil and gas activities, related prescribed projects listed under this Order include: oil and gas fields development; and construction of off-shore and on-shore pipelines in excess of 50 kilometres in length. For each of these projects, the project proponent must go through various processes which are part of the EIA requirements as preventive measures against potential environmental issues.

There are various opportunities to mitigate and prevent environmental impacts derived from each of these processes. For example, the key issues of concern in an offshore field development would include gaseous emissions; produced water and drilling discharges; accidental spills and leaks; waste management; and hazardous material handling.

Under section 34A, it is a mandatory requirement for the project proponent to go through these EIA processes and to submit the report. Thus, it is an offence if any person failed to submit such report or failed to abide by conditions stipulated in the report. Criminal sanction will be imposed on those who contravene this section in a form of a fine of up to Ringgit Malaysia (RM) 100 000, or jail of up to five years, or both.

\section{INTERNATIONAL LAW}

Apart from the application of domestic law to control marine pollution, the protection of the marine environment in Malaysia is also the subject of a number of international conventions [11][12]. At present, Malaysia is already a party to various treaties that deal with marine pollution, including, United Nations Convention on the Law of the Sea, 1982 (UNCLOS); International Convention for the Prevention of Pollution from Ships, 1973, as modified by the Protocol of 1978 relating thereto (MARPOL 73/78); International Convention on Oil Pollution Preparedness, Response and Co-operation (OPRC), 1990; International Convention on Civil Liability for Oil Pollution Damage, 1992 (the 1992 CLC); International Convention on the Establishment of an International Fund for Compensation for Oil Pollution Damage 1992 (the 1992 Fund Convention); Convention on Civil Liability for Bunker Oil Pollution Damage 2001 (Bunkers Convention); and Convention for the Limitation of Liability for Maritime Claims 1976 as Amended by Protocol 


\section{of 1996 (LLMC 1996).}

In general, these treaties contain provisions affecting rights and duties of nationals of the states parties on matters relevant to marine protection. Thus, each state is bound to make sure that these rights and duties are consistent with the requirements of the treaty. According to the domestic law of Malaysia, this may require the enactment of a statute by the Parliament, allowing such treaty to become part of the law of Malaysia.

\section{The EXClusive ECONIMIC Zone ACT 1984}

Until presently, there have been a number of legislations passed for the purpose of implementing such treaties, thus grating Malaysia additional rights, duties and jurisdictions on matters relevant to marine protection. Additionally implementation of these treaties also helps overcome limitations of domestic law particularly in relation to their territorial jurisdiction.

One example in point is in the case of the Environmental Quality Act 1974. While the scope of this Act in dealing with different sources of marine pollution is wide, its one pertinent limitation is its jurisdictional limit over the control of marine pollution. Its enforcement power is restricted only to the Malaysia's territorial water of within 12 nautical miles. Thus, the Act is not enforceable on any pollution offences committed beyond that boundary. Nevertheless, the control of marine pollution that took place beyond that territorial limit and up to 200 nautical miles of Malaysia's maritime territory is regulated under a different legislation, namely the Exclusive Economic Zone Act 1984.

As a mean of implementing obligations under the international law, The Exclusive Economic Zone Act 1984 has been amended in order to include provisions of UNCLOS 1982. Part IV of the Act deals with the protection and preservation of marine environment and is crucial in dealing with marine pollution control. Specifically, Part IV ascertains Malaysia's sovereign-rights in exploiting its natural resources in the exclusive economic zone (EEZ), which must also be in compliance with Malaysia's environmental policies as well as in accordance with its duty to protect and preserve the marine environment in the zone.

A stringent sanction is provided for under this Act regarding polluting the zone. Under section 10 , it is an offence to discharge any oil, mixture containing oil or pollutant into the EEZ from any vessel, land-based source, installation, device or aircraft, from or through the atmosphere or by dumping. This requirement is applied to the owner or occupier of vessel, place, device or aircraft, where upon conviction each shall be liable to a fine of not exceeding one million Ringgit. Under section 14, where Malaysia's coastline or any segment or element of the environment or related interest, including fishing, in the EEZ is damaged or is threatened to be damaged as a result of a discharge or escape, a direction may be issued to any person to take actions to remove, disperse, destroy or mitigate the damage or threat of damage.

Penalty imposed on any person who fails to comply with these directions is a fine not exceeding Ringgit Malaysia (RM) 10 000. It is also a requirement under section 12 for any discharge of oil, mixture containing oil or pollutant into the EEZ to be reported, as otherwise it would also be an offence. In addition, criminal sanction is also imposed on any person who fails to comply with directions to remove, disperse, destroy or mitigate damage by pollution as provided in section 14 of the Act.

\section{Merchant ShipPING ORdinance 1952}

Another Malaysian legislation that deals with marine pollution control is the Merchant Shipping Ordinance 1952. This Ordinance is considered to be the oldest law on merchant shipping, adopted on the basis of the British Merchant Shipping Act. This Ordinance has been amended regularly over the years, particularly in response to changes and requirements of international law.

Recently, the Merchant Shipping (Amendment and Extension) Act 2011 was enacted to extend the specified provisions of the Merchant Shipping Ordinance 1952 to the East Malaysian states of Sabah and Sarawak. It was also amended to provide for matters that include the implementation of the Convention on Limitation of Liability for Maritime Claims 1976 as amended by the Protocol of 1996.

The Merchant Shipping Ordinance 1952 has an important function towards marine pollution control when it was amended in 1991 to allow for the insertion of a new Part VA on "Pollution from Ships", the Ordinance was further amended in 2011 to extend its limit of territorial jurisdiction from the 12 nautical miles of the Malaysian waters to that of the 200 nautical miles of the EEZ. The combined effect of these amendments allows for a more comprehensive coverage of pollution control regulation under this Ordinance.

Specifically, under the newly inserted section 306CA, the prohibition against the discharge of oil or harmful substances into any part of Malaysian waters is now extended to cover that of the EEZ, atmosphere, any Malaysian coast or Malaysian reef. The word "discharge" for the purpose of section 306CA is elaborated by section 306C to mean "any release of oil or harmful substances, howsoever caused, from a ship and includes any escape, disposal, spilling, leaking, pumping, emitting or emptying...”.

Additionally, under the new section 306D, in a situation where there is an escape or likely escape of oil or harmful substance that may pollute or likely to pollute Malaysian waters , Malaysian coast, Malaysian reef or the EEZ, a notice may be issued to the owner of the ship requiring them to take steps to prevent or reduce the pollution. Under section 306F, if the notice is not complied with, the owner, if found guilty of the offence, will be liable to a fine not exceeding Ringgit Malaysia (RM) 50000 per day throughout the default period.

\section{The Merchant Shipping (Oil Pollution) ACT 1994}

Considering the severity of the impact of oil pollution on the marine biodiversity, and the fact that Malaysia's seas are most susceptible to vessel-based pollution, Malaysia's legal regime pertaining to oil pollution control has to be dynamic. Thus, apart from relying on criminal sanction to impose 
punishment and ensure deterrence, civil liability in the form of payment of compensation is also imposed on any vessel that caused damage due to the discharge of oil into the sea.

In this context, the type of oil pollution damage that can be claimed by the Malaysian government and other victims against the ship-owner is wide. They include property damage, the cost of clean up operations at sea and on-shore, economic loss suffered by those engaged in the fishing or marine culture industries and tourism sector, and the cost of reinstatement of the environment. Such liability is provided by a specific legislation, namely the Merchant Shipping (Oil Pollution) Act 1994. This legislation was enacted as an expansion of Malaysia's jurisdiction in respect of civil liability for marine oil pollution.

Basically, the passing of this Act is meant to give legal effect to two international treaties, the 1969 International Convention on Civil Liability for Oil Pollution Damage, and the 1971 International Convention on the Establishment of an International Fund for Compensation for Oil Pollution Damage. These two Conventions were amended by Protocols in 1992, and when Malaysia acceded to them in 2005, the Merchant Shipping (Oil Pollution) Act 1994 was amended to incorporate changes under the 1992 Protocols. For Malaysia, the significant advancement of this Act is the expansion of Malaysia's marine pollution control jurisdiction to include not only the territorial waters, but also the EEZ.

Another significant advancement of the Merchant Shipping (Oil Pollution) Act 1994 is the expansion of its scope to include that of "bunker oil". Previously, the Act only deals with pollution damage due to the escape of "oil", without any reference to "bunker oil". For this reason, the Act was again amended in 2011 through the Merchant Shipping (Oil Pollution)(Amendment)Act 2011 Act A1394 to include the discharge of bunker oil from any ship. The amendment was made when, in 2008, Malaysia acceded to the International Convention on Civil Liability for Bunker Oil Pollution Damage 2001.

The new amendment defines "bunker oil" as "any hydrocarbon mineral oil, including lubricating oil, used or intended to be used for the operation or propulsion of the ship, and any residues of such oil”. Generally, bunker oil is used to drive ships' engines and has been historically the most persistent form of oil pollution. It is very difficult to clean up and can have a potentially devastating impact on marine and coastal wildlife. The aim of the 2001 Convention is to ensure adequate, prompt and effective compensation to persons who suffer damage caused by spills of oil carried as fuel in ships' bunkers. The Convention also fills a significant gap in the regulations on marine pollution liability by establishing a liability and compensation regime for spills of oil carried as fuel in ships' bunkers. This requirement is provided within the new section 3A of the Merchant Shipping (Oil Pollution) Act 1994 which imposes liability on owners of ships for any damages due to bunker oil pollution in area of Malaysia.

Specifically, the Convention makes the ship owner 'strictly liable' for the damage that results from bunker oil that escapes from the ship. The Convention also makes it compulsory for all ships exceeding 1,000 gross registered tonnage to have insurance or other financial security. The aim of the 'compulsory insurance' is to ensure that the registered ship owner has the financial capacity to pay compensation for damage caused by bunker oil pollution.

For Malaysia, the significant advancement of this Act is the expansion of Malaysia's marine pollution control jurisdiction to include not only the territorial waters, but also the EEZ and imposes strict liability on the owner of the ship for pollution damage caused by the ship in any territorial sea of Malaysia or the or EEZ.

\section{The Malaysian ENFORCEMENT AgEnCy ACT 2004}

In recent times, Malaysia enacted yet another important maritime related legislation, namely the Malaysian Maritime Enforcement Agency Act 2004. The main objective of the Act is to provide for the establishment of a sole marine enforcement agency with the task of ensuring the safety and security of the Malaysian Maritime Zone, and protecting maritime and other national interests.

Under this Act, the scope of the "Malaysian Maritime Zone" is very wide and includes "the internal waters, territorial sea, continental shelf, exclusive economic zone and the Malaysian fisheries waters and the air space over the Zone" and thus it covers all the maritime areas of Malaysia.

In the context of comprehensive enforcement of marine pollution law in Malaysia, the enactment of this Act is commendable as it seeks to complement and harmonize the enforcement of existing maritime legal regime through the establishment of an agency known as the Malaysian Maritime Enforcement Agency. This Agency and its members are part of the Malaysian civil service and report directly to the Prime Minister's Department [13].

While the general aim of the establishment of this Agency is to improve Malaysia's maritime safety and security forces, the Agency is also responsible for the control and prevention of maritime pollution, and is given the power under section 6 of the Act to enforce law and order under any federal law of Malaysia. Because of its far reaching law enforcement powers in the Malaysian Maritime Zone, the Agency has a crucial role to play in consolidating and enforcing all the laws regarding marine pollution.

\section{CONCLUSION}

Physical features and geographical location of Malaysia indicate her dependence on the sea for economic and other purposes. Thus this imposes a responsibility for this country to protect her marine biodiversity against various harms, including pollution. Pollution of the sea is a national concern as it has an irreparable ecological impact on the marine environment unless effective steps are taken to prevent, mitigate, control or remove it.

Being a maritime nation, Malaysia has to take measures to ensure that her marine protection law continues to be dynamic to deal with the various sources of marine pollution. The experience has shown that while existing legislations in Malaysia are adequate for the control of marine pollution, they are based upon a fragmented approach to the control of such pollution [14]. Thus, one of the biggest challenges faced by Malaysia is in dealing with maritime law enforcement that is sectoral in nature and not uniformed. 
The establishment of the Malaysian Maritime Enforcement Agency is one way for the country to effectively cope with, and coordinate, the enforcement of these piecemeal laws. Although it is still premature to gauge the end result of the implementation of such planning, crucial developments in this area are nevertheless taking place as previously highlighted by this paper. These developments are reflections of changes that are taking place within the legal regime towards a more comprehensive and effective control of marine pollution for the betterment of marine biodiversity conservation.

\section{REFERENCES}

[1] A. G. Mazlan, et al. (eds.). "On the current status of coastal marine biodiversity in Malaysia,” Indian Journal of Marine Sciences, vol. 34(1), 2005, pp. 76-87.

[2] Department of Environment, Malaysia Environmental Quality Report 2009. Kuala Lumpur: Department of Environment, 2010, pp. 56-59.

[3] Malaysian Maritime Enforcement Agency, Annual Report 2009. Kuala Lumpur: Malaysian Maritime Enforcement Agency, 2010, p.23.

[4] M. Mustafa, Environmental Law in Malaysia. The Netherlands: Kluwer Law International, 2011, pp. 53-57.
[5] D. Hassan, Protecting the Marine Environment from Land-Based Sources of Pollution. Hampshire: Ashgate, 2006, p. 2.

[6] Department of Environment, Annual Report 2009. Kuala Lumpur: Department of Environment, 2010, pp. 40-121.

[7] Department of Environment, Procedure and Guidelines of the Marine Pollution Enforcement.. Kuala Lumpur: Department of Environment, 1995, pp. 3-19.

[8] M. Ariffin, “Toxic and hazardous waste management: Legal strategies in Malaysia,” CLJ Quarterly Law Review, vol.1, 2006, pp. 18-31.

[9] M.Ariffin, "Hazardous wastes and illegal dumping in Malaysia: An overview,” $M L J$, vol. 3, 2007, p. clx; MLJA, vol. 3, 2007, p.160.

[10] Department of Environment, Environmental Impact Assessment Guidelines for Petroleum Industries. Kuala Lumpur: Department of Environment, 1995.

[11] A. G. Hamid, "Judicial application of international law in Malaysia: A critical analysis”, Asia-Pacific Yearbook of International Humanitarian Law, vol.1, 2005, pp.196-214.

[12] A. G. Hamid, “Malaysia’s commitments under international conventions and the need for a harmonized legal regime regulating marine pollution,” $M L J$, vol.6, 2007, pp.124-148

[13] S. Kamin, "Enforcing ship-based marine pollution for cleaner sea in the Straits of Malacca,” Environmental Asia, vol. 3 (special issue), 2010, pp.61-65.

[14] M. Mustafa, “The Environmental Quality Act 1974: A significant legal instrument for implementing environmental policy directives of Malaysia,” IIUM Law Journal, vol. 19 no. 1, 2011, pp.1-34. 